\title{
The New Model of the Tax Vocational Education and the Application of Knowledge Management in China
}

\author{
Yue Wang, Gongliang Tang \\ The School of Public Finance and Taxation, Central University of Finance and Economics, Beijing, P. R. China \\ Email address: \\ 2016110019@email.cufe.edu.cn (Yue Wang),yansuo16@163.com (Gongliang Tang)

\section{To cite this article:} \\ Yue Wang, Gongliang Tang. The New Model of the Tax Vocational Education and the Application of Knowledge Management in China. \\ Education Journal. Vol. 8, No. 5, 2019, pp. 196-201. doi: 10.11648/j.edu.20190805.14
}

Received: July 22, 2019; Accepted: August 10, 2019; Published: August 23, 2019

\begin{abstract}
The tax vocational education aims at training professional talents needed to develop the tax undertaking. It is the basis for cultivating tax talents. High-quality tax civil servants are among the guarantees in facilitating the tax modernization undertaking. China's tax vocational education has made many achievements, but still with some problems. Under new situations, the tax vocational education in China is faced with a transformation from the academic education to the vocational cultivation. As a product of the internet era, Knowledge management fully embodies the thinking patterns of the "internet +" as "platform", "crossing boundaries" and "integration". Introducing knowledge management into tax vocational education and carrying out systematic and scientific design and planning is an innovation of tax education form, and it has more flexibility in application. It is more conducive to the inheritance of experience and the improvement of the efficiency of knowledge transformation. It is also conducive to the construction of tax culture and the formation of knowledge sharing, innovation and application consciousness, so as to better serve the implementation of fiscal reform and the development of tax modernization.
\end{abstract}

Keywords: Tax Vocational Education, Knowledge Management, Internet Plus, Knowledge Management System

\section{Development and Problems of the Tax Vocational Education}

Economy decides tax revenue which means the "new normal" of economy inevitably brings new characteristics to taxation which shoulders the mission of "collecting money for the country". Tax civil servants execute tax laws and taxation policies. Therefore, tax vocational education has always been the important foundation for tax talent construction. As "talents rejuvenate taxation and education first", without the reform and innovation of tax vocational education and the support of enough highly-competent tax professionals, the smooth progress of the fiscal and tax reform cannot be guaranteed, nor would taxation modernization be realized. The management of the tax vocational education and training before 1980's is mainly within the responsibilities of the personnel and education departments of the governmental financial system at all levels. By formulating and implementing relevant systems regarding the tax vocational education, these departments have been gradually bringing the tax vocational education on the right track in accordance with certain plans and steps. According to the guidelines of "emphasizing the shift, the structure and the improvement", tax vocational education in the 90 s enhanced teaching material construction, introduced modern teaching methods, improved the assessment system and infused ideological and political education, professional ethics education and discipline education into the content for further improvement of tax vocational education system [1]. Since the $20^{\text {th }}$ century, tax vocational education has undergone faster changes in concept and has attached importance to hierarchical management and conducted classified training, which has led to significant improvement of the teaching and management levels of vocational education teaching institutions, the constant improvement of their teaching material and scientific research system and the results in their standardized development [2].

At present, China's tax vocational education has achieved certain results. At this year's national tax system cadre education and training conference, Director Wang Jun pointed out that the current tax education work has made new progress in the field of routine work, and explored new forms of leadership training, digital personnel testing and so on. As of 2016, the whole tax system has vigorously promoted the 
strategy of "strengthening tax by talents". The national tax system has 34238 graduate students or above, accounting for $4.59 \%$ of the total number; more than 9000 professionals and 2000 backbone professionals have been selected, more than 2800 people have been selected into the talent pool of the State Administration of Taxation, and more than 500 people have been selected for the Five-term training of tax leaders. Deeply carry out "post training, business competition" activities, and concentrate on strengthening knowledge training. With the "Internet + tax education and training" as the carrier, we will promote the construction of network education and training platform resources, set up more than 320 courses, and the total number of courseware on the network platform is 450 , and users attend 356118 courses of various courses and online examinations [3]. In 2016, the Interactive Center of Network Platform was opened, including 6 categories and 18 webpages. "12366" Tax Service Hotline incorporates tax business consultation, service complaints and tax-related reports into the scope of service and acceptance, and becomes an external platform integrating three types of business.

At present, China's tax vocational education has made many achievements, but it is undeniable that there are still some problems. They are mainly manifested in the lack of flexibility in educational forms, the need to further strengthen the innovation, the relatively single forms of training, the systematic elaboration of theories by lecturers in accordance with chapters. These measures take reception learning as the main part and discovery learning as the supplement. They are stable and basic, following the traditional one-way transmission teaching method and regarding the educated as merely the recipients of knowledge [4]. This has led to loose connection between the education and training content and practical work which results in little such effect as training to meet the requirements, and slow knowledge update and training content's failing to change according to the market change. Our country's tax education at present is faced with the profound transformation from the traditional teaching mode of imparting academic principles with emphases on fiscal and tax theory and the study of the tax knowledge system. Under the new circumstances of pushing forward the construction of the "six major systems" of tax modernization, tax education and training require further reform and innovation to better implement the principle of "serving the overall interests and teaching to meet the requirements".

\section{The Forming of the Tax Vocational Cultivation Education Model}

The dogmatic recognition of the fiscal theory and tax knowledge system, the disconnection from the reality in the tax field and the lack of abilities to deal with tax affairs, and other denouncements are calling for an urgent transformation of the traditional tax education. The vocational cultivation education model aiming at training thinking skills and tax practical abilities is gradually rising. The transition from the academic imparting to the vocational cultivation should be matched with comprehensive revolutions of the educational philosophy, teaching methods, curriculum and knowledge scope. Merion, an American vocational educator, said that, the vocational education is mainly featured by being vocational, utilitarian and practical. This change can only be achieved through the joint participation across the tax professional community, including tax educators in colleges and universities and tax professionals. In terms of the transformation goal, the tax education contained in the tax professional community should avoid the tendency of simple craftsman training, and pay attention to the cultivation of versatile talents with strong innovative abilities, a critical spirit, multiple knowledge reserves and good professional accomplishments.

The transformation from the teaching mode of imparting academic principles to the vocational fostering mode requires tax education to adopt the cultivation concept that emphasizes thinking and skills and such teaching mechanism that meets society's requirements for tax education as case-based teaching. The practice-oriented teaching mode requires the feedbacks from the tax practical departments on the requirements and conditions in practice to the tax educators who also need to understand the conditions and problems in practice in the practical departments for analysis and solution through tax education and research. The close interaction between theory and practice means that the vocational fostering tax education is not only the responsibility and obligation of colleges and universities of finance and economics or educators and researchers, it also requires the joint participation of the entire community of tax professionals. Tax professionals being able to serve in practice and meeting the tax practical requirements guarantees the sound progress of the community of tax professionals.

\section{Knowledge Management and Its Application Values Against the Background of "Internet +"}

"The View of Knowledge" was first put forward in the literature of strategic management. Widely used classifications of knowledge are listed as follows. Nonaka believes that knowledge can be divided into explicit knowledge and tacit knowledge according to its attributes. Explicit knowledge is knowledge that can be coded, elaborated, communicated and recorded by symbols or languages. Tacit knowledge includes thinking models based on experience and behaviors and procedural cognitions for specific work [5]. According to the OECD research report, knowledge can also be divided into knowledge-why, know-how, know-what and know-who. Japanese managerial scientist Ichiro Nozawa put forward the law of knowledge transformation in the 1990s. He believed that knowledge transformation includes combination, implicitization, externalization and socialization. In recent years, scholars tend to regard knowledge as an important organizational resource. 
Widely-recognized knowledge management process includes knowledge construction, gathering, sharing, application and innovative circulation and conversion. Knowledge construction and gathering are the modularization of explicit knowledge and the externalization of tacit knowledge. Such explicit knowledge as various documents and materials are organized, gathered and stored systematically for convenient application and sharing; and tacit knowledge in the minds of the individuals needs to become explicit through communication, discussion and other relevant mining methods. The application and sharing of knowledge are the internalization of explicit knowledge and the socialization of tacit knowledge. The realization of knowledge application is usually grasping explicit knowledge (such as job requirements, summary of experience, case analysis, etc.) in the learning and organization of individuals through personal experience to realize the increase of persona tacit knowledge [6].

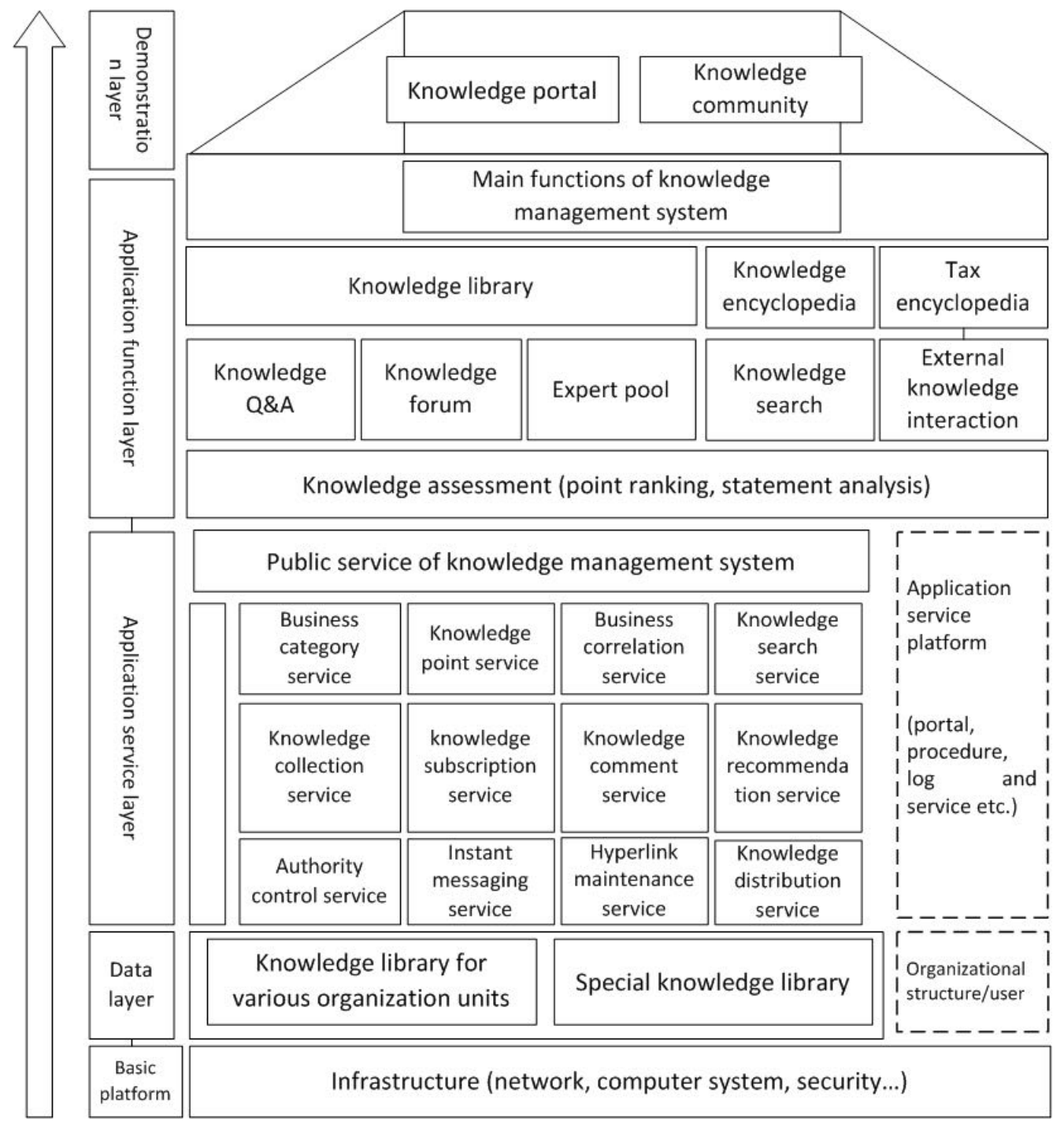

Figure 1. Tax knowledge management system.

With the development of the "internet + " development strategy, knowledge management, as the product of the internet era, has fully embodied the thinking of "internet +" such as "crossing boundaries", "integration", "platform" and others in the knowledge economy era [7]. Knowledge has become an important productive resource and plays an important role like other factors of production [8]. Tax modernization requires high-quality tax professionals who are skilled in business, professional in management and have a wide range of knowledge. Relevant knowledge related to tax profession, professional skills and work experience grasped by tax professionals form important knowledge resources of tax education. In order to promote the development of tax vocational education, knowledge management is introduced into the tax vocational education model, and knowledge management is planned systematically and scientifically.

\section{Paths to Introduce Knowledge Management into the Tax Vocational Education}

Based on China's national knowledge management standards and a great deal of industry knowledge management 
best practices by American Productivity and Quality Center (APQC), European Committee for Standardization and others, we should combine them with tax business characteristics and management requirements to design and apply knowledge management systems, so as to support the application and practice of knowledge management in an all-round way. A tax knowledge management system is composed of five layers, namely, the basic platform layer, the data platform layer, the application service layer, the application function layer and the application display layer. The basic platform layer includes networks, computer systems and other infrastructures, which provide basic guarantee for the normal operation of the knowledge management system. The data platform layer is mainly used to store data of the knowledge management system and build a tax knowledge base. The application service layer extracts the common functions of the knowledge management application functions to form application services, provide external interface services for business systems, such as the knowledge search and collection, and provides basic services for business systems. The application function layer mainly provides all kinds of application functions for the knowledge management. The application display layer provides basic services for tax business personnel through the portal technology. The application display layer provides interface integration for tax business personnel through the portal technology.

The main functions of bringing the knowledge management into the tax vocational education are as follows:

A knowledge base of hierarchical classifications. The relevant knowledge of tax profession is collected into database and classified according to tax businesses, tax departments, knowledge types and others. The business type dimension reflects the business characteristics of knowledge; the department type dimension reflects the management department of knowledge; the knowledge type dimension reflects the usages of knowledge. Construct a classified knowledge base to collect knowledge according to various dimensions under the framework of a basically unified classification system, so that tax professionals can query freely from different dimensions and quickly locate the required occupational-related knowledge. Classified query can cover the knowledge area, also can locate knowledge points, facilitate the systematic study of knowledge.

A quick, comprehensive and accurate knowledge map and an authoritative taxation encyclopedia. Taking a specific matter as a path, the knowledge related to the matter will be linked in series, such as the applicable basis, working procedures, computer operation guidelines, the number of forms, analysis of research reports, best practices, question answering, tax-related economic knowledge and other kinds of explicit knowledge and tacit knowledge. Tax terms can be divided into authoritative and referential terms. Authoritative entries are formulated according to the policies and documents of the State Administration of Taxation, while reference entries are formulated according to the working knowledge and practical experience of tax workers themselves, for sharing the understanding and experience of tax work.

A powerful information interaction platform, with the setting of the knowledge evaluation, the knowledge forum and the external transmission functions. Organization uncovers the hot topics of a certain period through knowledge assessment to grasp business trends. It also discovers talents through knowledge forums and quizzes. Tax professionals with rich experience can share their working experience and personal thoughts through quizzes and knowledge forums and then conduct knowledge mining and summarizes and refine the shared content into a written format to put into the knowledge base to help other staff members to jointly improve their work level. When evaluating typical cases during the work study involving tax payment appraisals, audit and anti-tax avoidance businesses, the experienced staff members should conduct analysis and exchange on such varied experience as introducing case origins, uncovering doubtful points, putting forward handling suggestions, existing problems and working experience, and compile outstanding cases to put into the knowledge base to further standardize and guide other staff members to carry out their work.

From the content of tax knowledge management, tax vocational education is a part of tax knowledge management. Education focuses on knowledge sharing. In addition, the content of tax knowledge management includes how to manage the process of knowledge production systematically and scientifically. Therefore, under certain conditions in management and technology, knowledge management concept, system and method can be introduced into tax vocational education, knowledge management can be thought over systematically and planned scientifically. Through the introduction of knowledge management, knowledge can be inherited and developed more comprehensively and effectively. It will serve the construction of tax talents, the reform of Finance and taxation and the modernization of taxation.

\section{Conclusion: The Role of Knowledge Management in Tax Vocational Education}

\subsection{Facilitating the Innovative Education and Making Learning and Applying Ways More Flexible}

Implementing the knowledge management in the organization, accumulating, sharing and applying valuable knowledge, broadening the ways for tax civil servants to improve their professional attainments. Comparing with the traditional teaching mode, the knowledge imparting process of knowledge management costs less and the knowledge imparting is of higher quality and not restricted to such factors as the level of trainers and the environment. Knowledge management also allows more convenient application. Implementing knowledge management provides more personalized leaning as knowledge could be arranged and 
modularized according to requirements from such multiple angels as business, item and department. It meets the personalized teaching needs based on the traditional teaching mode. It is a strong supplement to traditional vocational education. In the meantime, knowledge management allows more convenient application of knowledge in that the knowledge serving as basis for work could be used directly whereas such reference knowledge as experience and skills could be applied to work immediately with small adjustment according to specific actual situations.

\subsection{Favorable for the Transmission of Experience and the Application Efficiency of Knowledge}

By implementing the knowledge management to collect an collate knowledge, we can integrate scattered knowledge into a systematic knowledge base, so that tax department workers to search and apply knowledge efficiently in their study and work, improving their efficiency in applying knowledge and making the knowledge base "a toolbox" of tax department workers. Meanwhile, knowledge management constantly gathers and organizes personal knowledge into organization knowledge, which slows down the outflow of work experience due to job rotation and work efficiency would not suffer greatly due to personnel transfer. Knowledge management as the grip on standard law enforcement can provide unified and effective work bases, work specification and requirements to reduce law enforcement risks in the area of work operation procedure. In addition, it helps tax professionals expand thinking and have a more comprehensive understanding of their professional work through knowledge sharing and mining.

\subsection{Facilitating the Development of the Tax Culture and Promoting the Formation of Awareness of Learning, Sharing and Cooperating}

To promote the tax culture is important content of strengthening the cultivation of tax civil servants. We should strive to build a tax culture system with distinct and strong characteristics of the times and rich practical connotations, so as to take the tax culture as a guideline for the tax workers to forge ahead in terms of the spirit, system, behavior and work. The implementation of knowledge management encourages such ideas as "learning, sharing and cooperation" on the spiritual level and brings more standardized work on the system level, urging the tax professionals to form the habit of active learning, knowledge sharing and team cooperation, which forms a culture of active learning and a culture that encourages sharing and pushes for cooperation, providing strong impetus for taxation and tax administration.

\section{References}

[1] Ye Yingping, Chen Haitao, Chen Hao. Knowledge management process, technical tools, models and Countermeasures in the era of big data [J]. Library and information work, 2019, 63 (05): 5-13.
[2] Dong Xiaoying, $\mathrm{Hu}$ Yanni, Cao Jingjing. Knowledge Management in the Digital Economy Age: Challenges and Trends [J]. Library and Information Work, 2019, 63 (01): 60-64.

[3] Zhao Rongying, Wei Xuqiu. Gathering Knowledge into Wisdom: Knowledge Management Framework Model in Big Data Environment [J]. Intelligence Theory and Practice, 2017, 40 (09): 20-23.

[4] Chen Qin, Jiang Heli. Visual analysis of knowledge management research schools, knowledge base and hotspots in China [J]. Information Journal, 2016, 35 (02): 88-92+174.

[5] Yu Chengxian, He Dandan. Knowledge Management Strategy, Knowledge Integration Mechanism and Radical Innovation Research [J]. Science and Technology Management Research, 2015, 35 (21): 181-185.

[6] Wan Tao. Research on the Evaluation and Judgment Rules of Turning Tacit Knowledge into Explicit Knowledge [J]. Management Review, 2015, 27 (07): 66-75.

[7] Li Junsheng. China Tax Education Development Report 1949-2012 [M]. Beijing: Peking University Press, May 2013.

[8] Li Junsheng. China Tax Education Development Report 2013-2014 [M]. Beijing: Peking University Press, 2015, 5.

[9] Li Junsheng. China Tax Education Development Report 2015-2016 [M]. Beijing: Peking University Press, 2017, 5.

[10] Zeng Guanghui. Precision training, integration and innovation create a new situation in tax education and training $[\mathrm{J}]$. China Taxation, 2017, 7 .

[11] Chen Chen Chen. Japan's National Tax System Education and Training for China's Reference [J]. Tax Research, 2019 (03): 55-57.

[12] Zhu Shizhu. Deepening the research on the construction of training courses for tax cadres [J]. Tax Research, 2017 (11): 94-96.

[13] Zhu Shizhu. Key Points of Innovation in Tax Education and Training Reform [J]. Tax Research, 2016 (12): 100-103.

[14] Yan Guang Feng, Zhang Dong Ke. "Internet + vocational education" system structure and innovation application $[\mathrm{J}]$. Chinese audio-visual education, 2016 (08): 7-13.

[15] Wang Yongmin, Ma Qinghua, Yang Meilong. The Internal Training of Internet Enterprises and the Reference to Tax Departments [J]. International Taxation, 2015 (12): 72-73.

[16] Zhu Shizhu. On the Innovative Mechanism for Promoting the Training of Tax Cadres [J]. Tax Research, 2015 (08): 85-89.

[17] Theory and Practice of Civil Servant Training in Contemporary China [M]. People's Publishing House, Irving Han, 2010.

[18] Learning Books for Cadre Education [M]. Party Building Books Publishing House, Cadre Education Bureau, Organizational Department of the Central Committee of the Communist Party of China, 2012.

[19] Hong Zhaoping. Basic Practice and Reference Significance of Tax Talents Management in the United States and Japan [J]. Journal of Taxation College, Yangzhou University, 2009, 14 (03): 58-61. 
[20] The essence, characteristics and task of curriculum construction of tax specialized training course [J]. Zhu Shizhu. Tax economic research. 2014 (05).

[21] Wang Yongjun, Deng Wenshuo. Seeking the Normative Structure of Integrative Tax Knowledge System --- Also on the Framework of New Taxology and the Core Proposition of Tax Reform [J]. Tax Research, 2019 (06): 82-86.

[22] Zhang Yunhua, Shang Yongliang. Opportunities and Challenges of Tax Management in the Big Data Era [J]. Tax Research, 2018 (09): 76-81.

[23] Sun Cunyi, Tan Ronghua. Brief analysis of Internet plus wisdom taxation supported by big data [J]. tax research, 2018 (04): 104-107.

[24] Tang Huaan, Ding Ning, Zhu Qiuqin. The development strategy of "Internet + " tax information ecosystem, [J]. tax research, 2017 (04): 117-122., Guangdong, China.

[25] Sun Cunyi, Tan Ronghua. "Internet + tax" promotes the choice of tax big data analysis [J]. tax research, 2017 (03): 9-13.

[26] Wang Hongwei. Modernization of Tax Governance from the perspective of "Internet + " [J]. tax research, 2017 (03): 22-25.

[27] Lu Xiaochen, Qu Zhen, Ma Zefang, Zhang Fan. Application of Internet plus big data algorithm in tax work [J]. tax research, 2017 (02): 108-110.

[28] Guo Shunmin, Qi Zhen. "Internet + tax" promotes the path of modernization of tax administration [J]. tax research, 2016 (12): 111-114.

[29] Tang Yue, Wang Chao, Xue Jianqiu, Zhu Lan, Wei Junbo, Su Ping, Yan Liping, Ni Wei. The influence of big data on modern tax management under the background of "Internet $+"[\mathrm{~J}]$. tax research, 2016 (10): 108-112.

[30] Li Wanfu, Huang Lixin. Thoughts on the construction of "Internet plus tax big data application" [J]. tax research, 2016 (07): 45-48.
[31] Lei bin Yi. "Internet plus tax" to solve problems and promote ideas [J]. tax research, 2016 (05): 32-36.

[32] Wang Xing Ming. "Internet plus tax" - concept, practice and vision [J]. economic research reference, 2016 (11): 42-46.

[33] Mo Guan Hua. Discussion on promoting the modernization of tax administration in the era of "Internet $+"[\mathrm{~J}]$. economic research reference, 2016 (05): 48-51.

[34] Yu Jing. Exploration on Promoting Tax Governance in the Context of Big Data [J]. Tax Research, 2015 (10): 21-24.

[35] Ren Dongbiao, Fei Minghai, Yuan Mingchang. Exploration and analysis of the use of tax data in big data $[\mathrm{J}]$. Tax Research, 2015 (10): 25-28.

[36] Liu Lei, Zhongshan. An Analysis of Tax Administration in the Big Data Era [J]. Tax Research, 2015 (01): 89-92.

[37] Xie Bofeng. Construction of tax micro-data system in the era of big data [J]. Tax Research, 2015 (01): 92-95.

[38] Tan Ronghua, Jiao Ruijin. Some understandings about the application of big data in tax work [J]. Tax Research, 2014 (09): $3-5$.

[39] Research Group on the Training of High-level Professional Talents in Tax System, Mu Xinyong, Huang Ping'an, Wang Farong. On the Training of High-level Professional Talents in Tax System [J]. Tax Research, 2009 (09): 82-85.

[40] Ma Caichen, Zhang Deqing. Talent Development in Tax Department in the Perspective of Tax Reform: Current Situation, Problems and Policy Suggestions [J]. Guangdong Social Science, 2007 (05): 46-51.

[41] Xu Yuegang. Reflections on promoting tax education and training in an all-round way [J]. Tax Research, 2007 (08): 52-55. 